\title{
Effect of acetate Ringer's solution with or without $5 \%$ dextrose administered intravenously to diarrheic calves
}

\author{
Kenji TSUKANO ${ }^{1,2) *}$, Satoko KATO ${ }^{3)}$, Shinya SARASHINA ${ }^{3)}$, Izumi ABE ${ }^{4)}$, \\ Tadaharu AJITO ${ }^{4)}$, Hiromichi OHTSUKA ${ }^{1)}$ and Kazuyuki SUZUKI') \\ 1)School of Veterinary Medicine, Rakuno Gakuen University, 582 Midorimati, Bunnkyoudai, Ebetsu, \\ Hokkaido 069-8501, Japan \\ 2)Donan-NOSAI, Donan Agricultural Mutual Relief Association, 354-1 Oshamannbetyo, Azaoshamannbe, \\ Yamakoshi-gun, Hokkaido 049-3521, Japan \\ 3)Donan-NOSAI, Donan Agricultural Mutual Relief Association, 25-16 Misugityo, Yakumo, Futami-gun, \\ Hokkaido 049-3114, Japan \\ 4)Central Research Laboratories, Nippon Zenyaku Kogyo Co., Ltd., 1-1 Aza Tairanoue, Sasagawa, Asakamachi, \\ Koriyama, Fukushima 963-0196, Japan
}

J. Vet. Med. Sci.

79(4): 795-800, 2017

doi: 10.1292/jvms.16-0297

Received: 7 June 2016

Accepted: 23 February 2017

Published online in J-STAGE:

12 March 2017

\begin{abstract}
The objectives of this study were to evaluate the effects of intravenous acetate Ringer's solution, with or without dextrose, on diarrheic calves with either experimentally induced or spontaneous diarrhea. In the experimental model, diarrhea was induced in nine healthy calves by administering cold milk (below $4^{\circ} \mathrm{C}$ ) twice a day for 2 days. The calves were randomly assigned to the isotonic saline (ISS), acetated Ringer's (AR) or acetated Ringer's with 5\% dextrose (ARD) groups, with three calves assigned to each group. The calves received $80 \mathrm{~m} / \mathrm{kg}$ of their designated solution, at a flow rate of $20 \mathrm{~m} / \mathrm{kg} / \mathrm{hr}$. Infusion of ISS, AR and ARD were all found to be safe and effective in increasing plasma volume. Intravenous (IV) infusion of ISS resulted in the acidification secondary to dilution, while AR and ARD infusion inhibited acidification. In addition, prevention of catabolism was observed only with IV infusion of ARD. Sixteen calves with spontaneous diarrhea were enrolled in the clinical study. The calves were randomly assigned to the AR or ARD groups, with eight calves being assigned to each group. The calves received $100 \mathrm{~m} / \mathrm{kg}$ of their designated solution, at a flow rate of $25 \mathrm{~m} / \mathrm{kg} / \mathrm{hr}$. Intravenous infusion of AR and ARD was found to be effective in increasing plasma volume and inhibiting acidification. Only infusion of ARD prevented catabolism, but it also led to hyperglycemia. Our results suggest that a solution containing dextrose may be beneficial for wasting diarrheic calves.
\end{abstract}

KEY WORDS: acetate Ringer's solution, beta-hydroxybutyrate, calf, catabolism, diarrhea

Neonatal diarrhea remains the most common cause of death in beef and dairy calves, and is a major source of economic loss in the cattle industry [18]. Enterotoxigenic Escherichia coli (ETEC), and Cryptosporidium parvum, rotavirus and coronavirus appear to be the most important causes of infectious calf diarrhea. Calves are more sensitive to fluid loss than adult cattle, because of their higher total body water content and higher extracellular fluid volume. In addition, metabolic acidosis can occur secondary to diarrhea contingent on its severity and duration [22]. Intravenous (IV) fluid therapy is important for decreasing mortality associated with diarrhea in calves.

Use of bicarbonate precursors, such as sodium acetate and sodium lactate, carries minimal risk in the treatment of mild metabolic acidosis in calves [15]. Acetate Ringer's (AR) solution is preferred to correct moderate metabolic acidosis in calves [4]. Commercial AR solutions contain $28 \mathrm{mM}$ of sodium acetate as the bicarbonate precursor. Calves can easily metabolize acetate ions, which have an alkalizing effect [12] in muscle [2, 18]. Naylor et al. [17] demonstrated that acetate ions have alkalizing effects similar to bicarbonate in healthy calves. Another study showed that IV infusion of AR was effective in increasing plasma volume and correcting metabolic acidosis in diarrheic calves [15].

Malabsorptive diarrhea in calves results in decreased absorption of not only electrolytes and water, but also carbohydrates, lipids and amino acids [8]. Diarrheic calves also become anorexic. Todd et al. [23] reported that lack of food intake for $30 \mathrm{hr}$ caused hypoglycemia and an increase in beta-hydroxybutyrate (BHBA) levels indicating lipid mobilization. Similarly, calves fed only electrolyte solutions developed significant increases in BHBA and nonesterified fatty acid concentrations, indicating

*Correspondence to: Tsukano, K., Donan-NOSAI, Donan Agricultural Mutual Relief Association, 354-1 Oshamannbetyo, Azaoshamannbe, Yamakoshi-gun, Hokkaido 049-3521, Japan. e-mail: tsukano_kenji@donan-nosai.or.jp

(C2017 The Japanese Society of Veterinary Science

This is an open-access article distributed under the terms of the Creative Commons Attribution Non-Commercial No Derivatives (by-ncnd) License. (CC-BY-NC-ND 4.0: https://creativecommons.org/licenses/by-nc-nd/4.o/) 
Table 1. Composition of ISS, AR and ARD used in this study

\begin{tabular}{lccccccc}
\hline & $\begin{array}{c}\mathrm{Na}^{+} \\
(\mathrm{mEq} / l)\end{array}$ & $\begin{array}{c}\mathrm{K}^{+} \\
(\mathrm{mEq} / l)\end{array}$ & $\begin{array}{c}\mathrm{Ca}^{++} \\
(\mathrm{mEq} / l)\end{array}$ & $\begin{array}{c}\mathrm{Cl}^{-} \\
(\mathrm{mEq} / l)\end{array}$ & $\begin{array}{c}\text { Acetate } \\
(\mathrm{mEq} / l)\end{array}$ & $\begin{array}{c}\text { Glucose } \\
(\mathrm{g} / \mathrm{d} l)\end{array}$ & $\begin{array}{c}\text { Osmolality } \\
(\mathrm{mOsmol} / l)\end{array}$ \\
\hline ISS & 154.0 & - & - & 154.0 & - & - & 285 \\
$\mathrm{AR}$ & 130.0 & 4.0 & 3.0 & 109.0 & 28.0 & - & 255 \\
$\mathrm{ARD}$ & 130.0 & 4.0 & 3.0 & 109.0 & 28.0 & 5.0 & 566 \\
\hline
\end{tabular}

ISS: Isotonic sodium solution, AR: Acetate Ringer's solution, ARD: Acetate Ringer's solution with 5.0\% dextrose.

that these calves had a profound negative energy balance [5]. The mean fat content of feces was higher in calves with diarrhea than in healthy calves, and the mean caloric uptake from milk decreased by $31 \%$ in diarrheic calves compared to that in healthy calves. Negative energy balance continues throughout the course of illness [25]. This suggests that diarrheic calves need more energy for maintenance. Normally, brain and red blood cells use glucose as an energy source. When stores of glucose are low, gluconeogenesis is activated. Therefore, maintenance of glycometabolism is important to prevent muscle catabolism and lipolysis. The addition of dextrose to IV fluid solutions is routinely used to provide energy [4]. The addition of dextrose to IV fluid solutions intraoperatively suppresses protein catabolism and the formation of ketone bodies in humans [19, 24]. For the same reason, the addition of dextrose to IV fluid solutions may be useful for the treatment of calves with wasting diseases, such as diarrhea.

The objectives of this study were to evaluate the effects of the intravenous administration of solutions with or without dextrose on diarrheic calves, and to monitor BHBA concentrations as an index of lipid mobilization.

\section{MATERIALS AND METHODS}

All procedures were performed in accordance with the National Research Council Guidelines for the Care and Use of Laboratory Animals (National Academy Press, 1996). The following fluids were used: isotonic saline (ISS; Doubutuyou seisyoku- V injection: Nippon Zenyaku Kogyo Co., Ltd., Fukushima, Japan), acetated Ringer's (AR; Sakusan Ringer's- V injection: Nippon Zenyaku Kogyo Co., Ltd.) and acetated Ringer's with 5\% dextrose (ARD; Prototype: Nippon Zenyaku Kogyo Co., Ltd.). Table 1 shows the composition of the different fluids used.

\section{Experimental model}

Two Holstein and four Jersey calves, $12.0 \pm 2.5$ days old with body weights of $34.5 \pm 5.8 \mathrm{~kg}$, were enrolled in the study. All calves had ad libitum access to starter, hay and water throughout the study. Three of the calves were used twice in this study after allowing a rest interval of more than 1 week. The calves were deemed healthy based on physical examination and hematologic analysis. All calves were clinically normal before the start of the experiment, as determined by vital signs, physical appearance, milk intake, and urine and feces production. Dryness and coolness of the mucous membranes, sinking of the eyes and eyelid skin tenting of approximately $0.5 \mathrm{sec}$ were the main clinical signs observed following the induction of diarrhea. All calves became dehydrated, and metabolic acidosis was induced secondary to diarrhea caused by the following acidification procedure. The calves were primed with cold milk, which was prepared by adding $400 \mathrm{~g}$ of commercial milk replacement powder (Mo-toku milk 02 for calf, Scientific Feed Laboratory Co., Ltd., Tokyo, Japan) to $3 l$ of cold water (below $4^{\circ} \mathrm{C}$ ). The milk was administered twice a day for 2 days through a feeding tube [15]. Before the start of and at the end of the acidification procedure, base excess (BE), hemoglobin concentration $(\mathrm{Hb})$ and BHBA were measured. A 14-gauge catheter (Surefrow Catheter SR-OT1464C, Terumo, Tokyo, Japan) was inserted into the right jugular vein of the conscious calves. The catheter was then connected to an ordinary drip tube that controlled the flow rate. The calves were randomly assigned to the ISS group ( $n=3$; IV infusion of ISS), AR group ( $n=3$; IV infusion of AR) or ARD group ( $\mathrm{n}=3$; IV infusion of ARD). The calves received $80 \mathrm{ml} / \mathrm{kg}$ of the designated solution, at a flow rate of $20 \mathrm{ml} / \mathrm{kg} / \mathrm{hr}$, resulting in a flow rate for the dextrose of $1.0 \mathrm{~g} / \mathrm{kg} / \mathrm{hr}$. Initiation of fluid infusion was designated as time 0 (base). Venous blood samples were collected at base, as well as $0.5,1,4$ and $24 \mathrm{hr}$ after initiation of fluid therapy. Venous blood samples were anaerobically collected in a heparinized $1-\mathrm{m} l$ syringe from the left jugular vein, and the tips of the syringes were capped after collection.

\section{Clinical study}

Sixteen diarrheic calves (nine Holstein males, four Holstein females and three crossbred (Holstein $\times$ Japanese Black) males) with a mean age of 9.6 \pm 3.1 days (range 5-14 days old) and a body weight of approximately $40.0 \mathrm{~kg}$ were enrolled in this clinical study. All calves had ad libitum access to starter, hay and water throughout the study. Dehydration and metabolic acidosis secondary to diarrhea were diagnosed in these calves by veterinary practitioners on the basis of physical examination and blood gas analysis (i-STAT 1, Abbott Lab., North Chicago, IL, U.S.A.). In 13 of the 16 calves (81.3\%), C. parvum was detected using a C. parvum rapid test kit (BOX-BIOK-155-10TEST, COSMO BIO Co., Ltd., Tokyo, Japan). A 14-gauge catheter (Surefrow Catheter SR-OT1464C, Terumo) was inserted into the right jugular vein and was connected to an ordinary drip tube that controlled the flow rate. The calves were randomly assigned to the AR ( $\mathrm{n}=8$; IV infusion of AR) or ARD groups ( $\mathrm{n}=8$; IV infusion of ARD). The calves received $100 \mathrm{ml} / \mathrm{kg}$ of AR or ARD, at a flow rate of $25 \mathrm{ml} / \mathrm{kg} / \mathrm{hr}$, resulting in a flow rate for the dextrose of $1.25 \mathrm{~g} / \mathrm{kg} /$ 

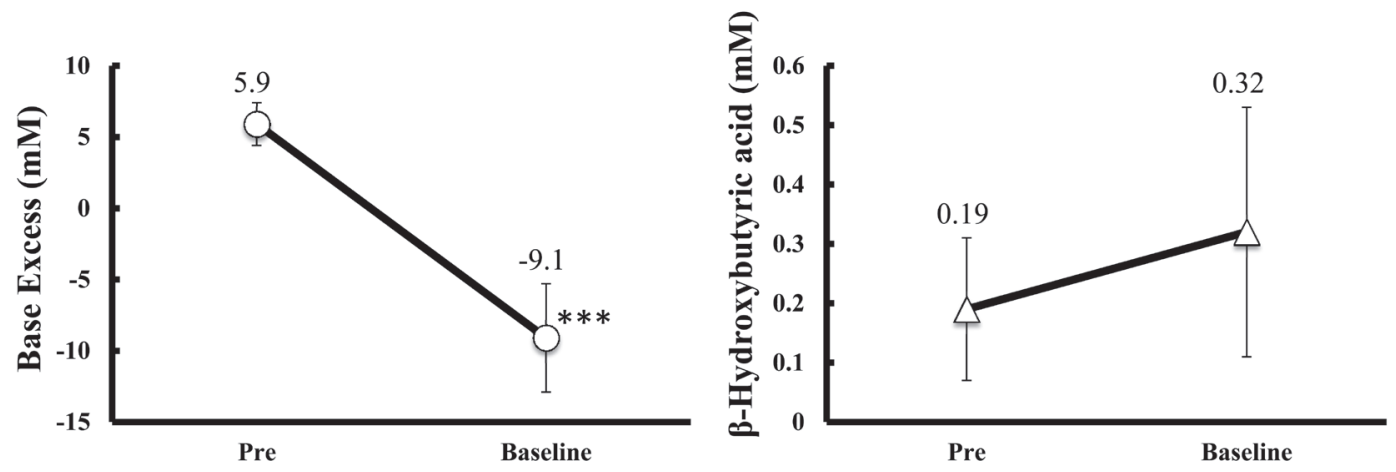

Fig. 1. Graphs depicting the changes in base excess (BE) and beta-hydroxybutyrate (BHBA) after the acidification procedure in the experimental model. Pre: before the acidification procedure, Baseline: at the end of the acidification procedure. ${ }^{* * *} P<0.001$, versus pre-values obtained via student's $t$-test or Mann-Whitney $U$-test following an $F$-test.

hr. Venous blood samples were collected at base, as well as $0.5,1,2,4$ and $24 \mathrm{hr}$ after initiation of fluid therapy. Venous blood samples were anaerobically collected in a heparinized $1-\mathrm{m} l$ syringe from the left jugular vein, and the tips of the syringes were capped after collection.

\section{Analysis}

Beta-hydroxybutyrate concentrations were analyzed in whole blood samples using an automatic analyzer (Precision Xceed, Abbott Lab.); hematocrit (Hct), Hb and BE were measured using an automatic gas analyzer (i-STAT 1, Abbott Lab.). Changes in relative plasma volume (rPV) were calculated from $\mathrm{Hb}$ and Hct, using accepted formulas [10].

\section{Statistical analysis}

Data are expressed as mean \pm standard deviation. In the experimental model and the clinical study, mean values for each dependent variable were compared with the base values within groups, using one-way ANOVA followed by Dunnett's test. Measured dependent variables in the experimental model were compared between groups for each sample collection period using one-way ANOVA followed by Tukey's HSD test. Measured dependent variables in the clinical study were compared between groups for each sample collection period using student's $t$-test or Mann-Whitney $U$-test following an $F$-test. The significance level was set at $P<0.05$.

\section{RESULTS}

\section{Experimental model}

Figure 1 shows the sequential changes in venous BE and BHBA measurements following the acidification procedure. The BE measurements decreased significantly, from $5.9 \pm 1.5$ to $-9.1 \pm 3.8 \mathrm{mM}(P<0.001)$. The BHBA levels increased from $0.19 \pm 0.12$ to $0.32 \pm 0.21 \mathrm{mM}$. Although this difference was not significant, the BHBA concentrations of all calves increased to $>0.2 \mathrm{mM}$. Therefore, the acidification procedure used in this study was deemed suitable for inducing metabolic acidosis and ketosis. Clinical signs, such as moist cough, jugular vein congestion, ptosis, salivation and arrhythmia, were not observed during the experimental period in any group. Moist lung sounds appreciated on auscultation, which were not associated with severe clinical signs, were present in 2/3 calves in the ISS group and 1/3 calves in the AR group. Urination was observed for the first time at $127.0 \pm 42.0$ $\min , 97.0 \pm 54.0 \mathrm{~min}$ and $39.0 \pm 19.0 \mathrm{~min}$ after initiation of fluid therapy in the ISS, AR and ARD groups, respectively.

The rPV of the ISS, AR and ARD groups increased steadily throughout the study period, reaching $124.7 \pm 14.2 \%, 136.3 \pm$ $18.2 \%$ and $120.9 \pm 8.0 \%$, respectively, at the end of fluid infusion $(=4 \mathrm{hr})$. The rPV was found to be significantly increased from the base values $(P<0.05$ by Dunnett's test). The sequential changes in rPV for the ISS, AR and ARD groups were not significantly different between the groups. The venous pH's of the ISS, AR and ARD groups did not change significantly from the base values until the end of fluid therapy: from $7.211 \pm 0.113,7.265 \pm 0.046$ and $7.300 \pm 0.037$ to $7.207 \pm 0.114,7.298 \pm 0.046$ and 7.308 \pm 0.018 , respectively. The $\mathrm{HCO}_{3}{ }^{-}$and $\mathrm{PCO}_{2}$ concentrations in the ISS, AR and ARD groups remained constant throughout the infusion period. The BE measurements from the ISS group were slightly decreased as compared with the base values until the end of fluid therapy, but these changes were not significant. Although the BE measurements from the AR and ARD groups were slightly increased at each time point compared with the base values, these changes were not significant. No significant changes in $\mathrm{BE}$ measurements in any of the groups were observed in this study. Figure 2 shows the sequential changes in the venous BHBA concentrations in the experimental model. The BHBA concentrations in the ISS and AR groups increased slightly, reaching $0.53 \pm$ 0.21 and $0.37 \pm 0.25 \mathrm{mM}$, respectively, at the end of infusion $(4 \mathrm{hr})$; these values did not significantly increase as compared with the base values. In contrast, ARD infusion induced progressive and significant decreases in BHBA concentrations, which reached 0 


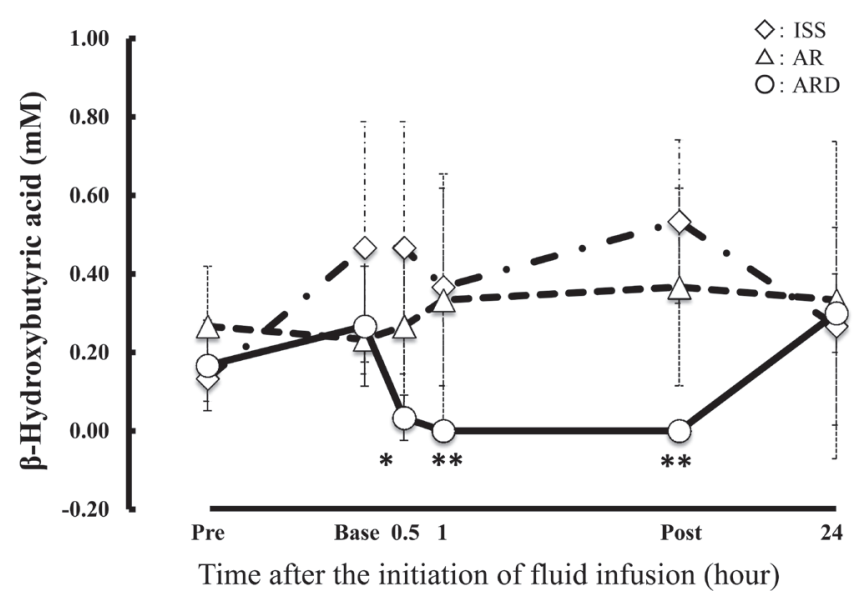

Fig. 2. Graph depicting the beta-hydroxybutyrate (BHBA) concentrations in the experimental model in calves administered ISS, AR or ARD. Pre: before acidification, Base: pre-infusion and Post: end of infusion. Levels of significance indicated; $* P<0.05$, $* * P<0.01$, versus pre-infusion values obtained via Dunnett's test.

$\mathrm{mM} 1 \mathrm{hr}$ after initiation of fluid therapy and remained at this level throughout the procedure $(P<0.05$ by Dunnett's test). The base values of plasma glucose in the ISS, AR and ARD groups were 50.0 \pm 21.7 , $73.3 \pm 21.5$ and $72.0 \pm 29.8 \mathrm{mg} / \mathrm{d} l$, respectively. Significant increases in plasma glucose concentrations were induced in calves receiving ARD, with values reaching $332.0 \pm 42.4 \mathrm{mg} / \mathrm{d} l 30 \mathrm{~min}$ after initiation of fluid therapy, and remaining between 364.0 and $414.0 \mathrm{mg} / \mathrm{d} l$ throughout the remainder of the procedure. The plasma glucose concentrations in the ARD group decreased slightly, reaching $42.0 \pm 6.2 \mathrm{~g} / \mathrm{d} l, 24 \mathrm{hr}$ after initiation of fluid therapy.

\section{Clinical study}

The calves received $100 \mathrm{ml} / \mathrm{kg}$ of AR or ARD, which was administered over $236.3 \pm 20.5 \mathrm{~min}$ or $232.5 \pm 29.0 \mathrm{~min}$, respectively. All calves observed had diarrhea, accompanied by dehydration and metabolic acidosis. Clinical signs of impaired central nervous system function including ataxia and coma were observed in some. During the fluid infusion, clinical signs, such as moist cough, jugular vein congestion, ptosis, salivation and arrhythmia, were not observed during the experimental period in either group. Moist rales noted on auscultation and trembling, neither of which were severe, were observed in $4 / 8$ calves in the AR group and $3 / 8$ calves in the ARD group. No calves died during the study period. Clinical signs of impaired central nervous system function and consistency of the feces did not change significantly in either group during fluid infusion. All calves were clinically dehydrated. The eyes were sunken 4 to $8 \mathrm{~mm}$ into the orbit, but there was no space observed between the eyelid and the eyeball until the end of fluid infusion in both groups. We monitored for urination at base, and at $0.5,1,2,4$ and $24 \mathrm{hr}$ after initiation of fluid therapy. Urination was observed in $3 / 8$ calves in the AR group and 1/8 calves in the ARD group. In 3/8 calves in the AR group, urination was observed once, and in $1 / 8$ calves in the ARD group, urination was observed twice during the study.

Figure 3 shows the rPV, BE and BHBA in calves receiving fluid infusions. The rPV of the AR and ARD groups increased steadily during the procedure, reaching $179.0 \pm 58.6 \%$ and $144.3 \pm 22.9 \%$, respectively, at the end of fluid infusion $(P<0.05$ by Dunnett's test). The sequential changes in rPV were not significantly different between the groups. The venous $\mathrm{pH}$ of the AR and ARD groups did not change significantly from baseline until the end of the fluid infusions; the values increased from $7.101 \pm$ 0.082 and $7.105 \pm 0.051$ to $7.192 \pm 0.061$ and $7.145 \pm 0.050$, respectively. The $\mathrm{HCO}_{3}{ }^{-}$and $\mathrm{PCO}_{2}$ concentrations in the $\mathrm{AR}$ and ARD groups remained constant throughout the infusion period. The BE measurements in $8 / 8$ calves in the AR group and $8 / 8$ calves in the ARD group were slightly increased compared with the base values until the end of fluid infusion, decreasing from $-15.8 \pm$ 4.7 and $-17.0 \pm 4.9$ to $-12.3 \pm 4.4$ and $-14.4 \pm 4.6 \mathrm{mM}$, respectively. However, these changes were not significant. The BHBA 
concentrations of the AR group slightly increased as compared with the base values until the end of fluid infusion, increasing from $0.21 \pm 0.08 \mathrm{mM}$ to $0.38 \pm 0.34 \mathrm{mM}$ at the end of infusion; however, these changes were not significant. In contrast, ARD infusion induced progressive and significant decreases in BHBA concentrations, which reached $0.06 \pm 0.05 \mathrm{mM}$ at the end of fluid infusion $(P<0.05$ by Dunnett's test). The sequential changes in BHBA concentrations for the ARD group were significantly greater than those for the AR group $(P<0.05)$. The base values of plasma glucose in the AR and ARD groups were $84.8 \pm 28.6$ and $79.4 \pm 16.2$ $\mathrm{mg} / \mathrm{d} l$, respectively. Significant increases in plasma glucose concentrations were induced in calves by ARD infusion, which reached $337.0 \pm 57.6 \mathrm{mg} / \mathrm{d} l 30 \mathrm{~min}$ after initiation of fluid therapy, and remained between 340.6 and $406.3 \mathrm{mg} / \mathrm{d} l$ throughout the procedure. However, plasma glucose concentrations returned to $84.9 \pm 19.4 \mathrm{mg} / \mathrm{d} l 24 \mathrm{hr}$ after initiation of fluid therapy. In the AR and ARD groups, plasma potassium concentrations decreased slightly throughout the procedure, reaching $4.3 \pm 0.7 \mathrm{and} 3.7 \pm 0.6 \mathrm{mEq} / l$, respectively, at the end of fluid infusion $(P<0.05)$. Plasma sodium and chloride concentrations did not change until the end of fluid infusion in both the AR and ARD groups.

\section{DISCUSSION}

In this study, IV infusion of both AR and ARD was found to be effective in increasing plasma volume and correcting BE. However, only IV infusion of ARD prevented catabolism. This suggests that it is necessary to use AR and ARD properly. Administration of AR is appropriate for the early stages of diarrhea typified by dehydration and metabolic acidosis, but which has not progressed to exhaustion. Meanwhile, ARD infusion may be beneficial for wasting diarrheic calves with dehydration and metabolic acidosis.

There are many consistent clinical and pathological changes observed in calves with diarrhea. The cholera toxin of Vibrio cholera and the heat labile toxin (LT) of E. coli cause secretory diarrhea [8]. In a clinical study, C. parvum was isolated from 13/16 diarrheic calves. Following infection, clinical signs peaked at 3 to 5 days and lasted for 4 to 17 days [6]. C. parvum damages the small intestinal villi, which results in failure of electrolyte and water absorption (malabsorptive diarrhea). Calves with diarrhea resulting in dehydration had increased D-lactate concentrations and a negative energy balance caused by anorexia and malabsorption of nutrients [20]. Hypoglycemia has been reported in diarrheic calves, which were found to be weak, lethargic or comatose [21]. Hypoglycemia, often occurring in combination with hyperlactatemia, was typically observed in the terminal stages of the disease [11]. Therefore, intravenous fluid therapy must supply sufficient sodium to normalize the extracellular fluid (ECF) volume, provide an alkalizing agent to correct the metabolic acidosis and provide energy because most calves that have diarrhea are in a state of negative energy balance [5]. In this study, we used an experimental model and a clinical study to evaluate whether dextrose administered intravenously to diarrheic calves was an effective treatment.

The acidification procedure used in this study significantly decreased the BE, from $5.9 \pm 1.5$ to $-9.1 \pm 3.8 \mathrm{mM}(P<0.001)$. In general, a calf with a $\mathrm{BE} \leq 15 \mathrm{mM}$ is diagnosed with severe metabolic acidosis [16]. Therefore, the acidification procedure used in this study was a suitable method for inducing mild acidosis.

In the experimental model, infusion of ISS, AR and ARD was found to be safe and effective in increasing plasma volume. There was no significant difference between the three groups in relative changes in plasma volume until the end of fluid therapy. In the clinical study, IV infusion of AR and ARD was found to be effective in increasing plasma volume. There was no significant difference between the AR and ARD groups in relative changes in plasma volume until the end of fluid therapy. These results indicate that both AR and ARD infusions are appropriate for the treatment of dehydrated calves. However, at the end of fluid therapy, the rPV of the AR group was found to have increased significantly than that of the ARD group. It is possible that osmotic diuresis caused hyperglycemia in the ARD group. A possible explanation for the difference in rPV was the distribution of fluid between the plasma and interstitial compartments in the ARD group. There appears to be a few differences between AR and ARD infusion used for the purposes of rehydration. Intravenous infusion of AR resulted in more rapid rehydration than did IV infusion of ARD.

In the experimental model, the relative changes in BE for the ISS group were slightly decreased at the end of fluid therapy. In the ISS group, the chloride concentration increased significantly, from $102.4 \pm 5.4 \mathrm{mmol} / \mathrm{l}$ at base to $107.5 \pm 4.6 \mathrm{mmol} / \mathrm{l}$ at the end of therapy $(P<0.05)$. Barker reported that IV infusion of $0.9 \%$ saline solution resulted in severe acidosis caused by increased serum chloride levels [3]. Therefore, the cause of the decrease in BE in the ISS group could be the increased serum chloride levels. This suggests that ISS may be of limited usefulness in calves with metabolic acidosis. In the experimental model, BE measurements in $2 / 3$ calves in the AR group and $2 / 3$ calves in the ARD group increased during fluid therapy. Similarly in the clinical study, BE measurements in $8 / 8$ calves in the AR group and 8/8 calves in the ARD group increased during fluid therapy. The changes were not significant in either the experimental model or the clinical study. There appears to be no difference between AR and ARD infusion in the correction of BE.

Intravenous infusion of ISS in the experimental model and IV infusion of AR in both the experimental model and the clinical study induced catabolism. Intravenous infusion of both ISS and AR led to increased BHBA concentrations. After rehydration, the $\mathrm{Na}^{+} / \mathrm{K}^{+}$-ATPase pump and Cori cycle could be activated in calves with diarrhea; both use energy in the form of ATP. Consequently, ISS and AR without dextrose did not prevent exhaustion. On the contrary, in both the experimental model and the clinical study, we demonstrated that IV infusion of ARD prevented catabolism. This suggests that the addition of dextrose maintains glycometabolism and inhibits increases in BHBA caused by lipolysis. In the experimental model, ARD infusion induced a rapid and significant decrease in BHBA. In the clinical study, ARD infusion resulted in significant decreases in BHBA values at the end of fluid therapy. This suggests that exhaustion occurred more severely in the clinical study than it did in the experimental model. 
Several investigators have reported that the addition of dextrose to fluids maintains blood glucose and inhibits glyconeogenesis. As a result, the breakdown of skeletal muscle and formation of ketone bodies in patients undergoing surgery is controlled [13, 19, 24]. Therefore, ARD containing 5\% dextrose may be useful for the treatment of wasting diseases like diarrhea. Infection with C. parvum has been shown to induce severe villous atrophy in calves [11], leading to malabsorptive diarrhea. Absorption is impaired due to the loss of mature villous epithelial cells and their associated transporters as well as a decrease in total surface area [7]. For prevention of catabolism and maintenance of adequate nutrition, the addition of dextrose to IV fluid solutions may be more effective than the oral administration of dextrose.

The addition of dextrose to IV fluid solutions may lead to hyperglycemia [1]. Increases in blood insulin may cause a rebound phenomenon after infusion of dextrose-containing fluids. In the experimental model used in this study, hypoglycemia was observed in the ARD group. Gareis et al. [9] reported that the addition of either 100 or $400 \mathrm{~g}$ of dextrose to $10 l$ of IV fluids containing saline and sodium bicarbonate (given over $24 \mathrm{hr}$ ) resulted in decreased milk intake in calves with neonatal diarrhea. Similarly, IV infusion of ARD may affect intake of milk or starter. Mcmanus et al. [14] reported that hyperglycemia led to immunosuppression during surgery in humans. Thus, several investigators have indicated that hyperglycemia is not a desired outcome following fluid therapy. Future studies are needed to determine an appropriate method of incorporating dextrose in IV fluid solutions.

ACKNOWLEDGMENTS. This study was supported by a Grant-in-Aid for Science Research from the Ministry of Education, Culture, Sports, Science and Technology of Japan (no. 26450431) to K. Suzuki.

\section{REFERENCES}

1. Amano, A., Mitsuse, T., Hashiguchi, A., Masuda, K., Jo, Y., Akasaka, T., Ogata, S. and Sato, T. 2003. [Anesthesia for cesarean section in a patient with transient diabetes insipidus]. Masui 52: 158-161. [Medline]

2. Ballard, F. J. 1972. Supply and utilization of acetate in mammals. Am. J. Clin. Nutr. 25: 773-779. [Medline]

3. Barker, M. E. 2015. 0.9\% saline induced hyperchloremic acidosis. J. Trauma Nurs. 22: 111-116. [Medline] [CrossRef]

4. Berchtold, J. 2009. Treatment of calf diarrhea: intravenous fluid therapy. Vet. Clin. North Am. Food Anim. Pract. 25: 73-99, vi. [Medline] [CrossRef]

5. Constable, P. D., Thomas, E. and Boisrame, B. 2001. Comparison of two oral electrolyte solutions for the treatment of dehydrated calves with experimentally-induced diarrhoea. Vet. J. 162: 129-141. [Medline] [CrossRef]

6. Fayer, R., Gasbarre, L., Pasquali, P., Canals, A., Almeria, S. and Zarlenga, D. 1998. Cryptosporidium parvum infection in bovine neonates: dynamic clinical, parasitic and immunologic patterns. Int. J. Parasitol. 28: 49-56. [Medline] [CrossRef]

7. Foster, D. M. and Smith, G. W. 2009. Pathophysiology of diarrhea in calves. Vet. Clin. Food. Anim. 25: 13-36.

8. Foster, D. M. and Smith, G. W. 2009. Treatment of calf diarrhea: intravenous fluid therapy. Vet. Clin. Food. Anim. 25: 73-99.

9. Gareis, A. 2003. Die bedeutung von glukosezusatz zur infusionslösung bei kälbern mit neugeborenendiarrhoe [Significance of glucose additions to infusions in calves with neonatal diarrhea] [thesis]. Munich: University of Munich [in German].

10. Greenleaf, J. E., Convertino, V. A. and Mangseth, G. R. 1979. Plasma volume during stress in man: osmolality and red cell volume. J. Appl. Physiol. 47: 1031-1038. [Medline]

11. Heine, J., Pohlenz, J. F., Moon, H. W. and Woode, G. N. 1984. Enteric lesions and diarrhea in gnotobiotic calves monoinfected with Cryptosporidium species. J. Infect. Dis. 150: 768-775. [Medline] [CrossRef]

12. Kasari, T. R. and Naylor, J. M. 1985. Clinical evaluation of sodium bicarbonate, sodium L-lactate, and sodium acetate for the treatment of acidosis in diarrheic calves. J. Am. Vet. Med. Assoc. 187: 392-397. [Medline]

13. Lattermann, R., Carli, F., Wykes, L. and Schricker, T. 2003. Perioperative glucose infusion and the catabolic response to surgery: the effect of epidural block. Anesth. Analg. 96: 555-562. [Medline]

14. McManus, L. M., Bloodworth, R. C., Prihoda, T. J., Blodgett, J. L. and Pinckard, R. N. 2001. Agonist-dependent failure of neutrophil function in diabetes correlates with extent of hyperglycemia. J. Leukoc. Biol. 70: 395-404. [Medline]

15. Nakagawa, M., Suzuki, K., Takahashi, F., Kamikatano, K., Koiwa, M. and Taguchi, K. 2009. Comparison of the alkalizing effects of bicarbonate precursors in calves with experimentally induced metabolic acidosis. J. Vet. Med. Sci. 71: 807-809. [Medline] [CrossRef]

16. Naylor, J. M. 1989. A retrospective study of the relationship between clinical signs and severity of acidosis in diarrheic calves. Can. Vet. J. 30: 577-580. [Medline]

17. Naylor, J. M. and Forsyth, G. W. 1986. The alkalinizing effects of metabolizable bases in the healthy calf. Can. J. Vet. Res. 50: 509-516. [Medline]

18. Sabine, J. R. and Johnson, B. C. 1964. Acetate metabolism in the ruminant. J. Biol. Chem. 239: 89-93. [Medline]

19. Schricker, T., Lattermann, R. and Carli, F. 2005. Intraoperative protein sparing with glucose. J. Appl. Physiol. 99: 898-901. [Medline] [CrossRef]

20. Smith, G. W. 2009. Treatment of calf diarrhea: oral fluid therapy. Vet. Can. Food Anim. 25: 55-72.

21. Tennant, B., Harrold, D. and Reina-Guerra, M. 1968. Hypoglycemia in neonatal calves associated with acute diarrhea. Cornell Vet. 58: 136-146. [Medline]

22. Tennant, B., Harrold, D. and Reina-Guerra, M. 1972. Physiologic and metabolic factors in the pathogenesis of neonatal enteric infections in calves. J. Am. Vet. Med. Assoc. 161: 993-1007. [Medline]

23. Todd, S. E., Mellor, D. J., Stafford, K. J., Gregory, N. G., Bruce, R. A. and Ward, R. N. 2000. Effects of food withdrawal and transport on 5- to 10-day-old calves. Res. Vet. Sci. 68: 125-134. [Medline] [CrossRef]

24. Yamasaki, K., Inagaki, Y., Mochida, S., Funaki, K., Takahashi, S. and Sakamoto, S. 2010. Effect of intraoperative acetated Ringer's solution with $1 \%$ glucose on glucose and protein metabolism. J. Anesth. 24: 426-431. [Medline] [CrossRef]

25. Youanes, Y. D. and Herdt, T. H. 1987. Changes in small intestinal morphology and flora associated with decreased energy digestibility in calves with naturally occurring diarrhea. Am. J. Vet. Res. 48: 719-725. [Medline] 